\title{
Bortezomib-based treatment for relapsed and refractory angioimmunoblastic T-cell lymphoma: Case report and literature review
}

\author{
SHUYAN LIU*, ZHENGANG YUAN*, CHUNYANG ZHANG, WEIJUN FU and JIAN HOU \\ Department of Hematology, Shanghai Changzheng Hospital, The Second Military Medical University, \\ Shanghai 200003, P.R. China
}

Received February 15, 2012; Accepted May 14, 2012

DOI: $10.3892 / \mathrm{ol} .2012 .724$

\begin{abstract}
Angioimmunoblastic T-cell lymphoma (AITL) is a distinct peripheral T-cell lymphoma (PTCL) subtype, accounting for $15-20 \%$ of PTCL and $2 \%$ of all non-Hodgkin lymphoma (NHL), with a poor prognosis. In the present study, we describe a 76-year-old patient with AITL who failed to respond to conventional chemotherapy but responded to bortezomib-based treatment and demonstrated persistent clinical improvement at the 18-month follow-up. These data suggest that bortezomib-based treatment may be a reliable, safe and effective alternative for treating relapsed/refractory AITL.
\end{abstract}

\section{Introduction}

Angioimmunoblastic T-cell lymphoma (AITL) is a distinct peripheral T-cell lymphoma (PTCL) subtype with uncommon clinical and pathological features, accounting for $15-20 \%$ of PTCL and 2\% of all non-Hodgkin lymphoma (NHL). However, there is no consensus with regard to the best approach for treating patients with AITL and the disease often follows an aggressive clinical course. AITL portends a poor prognosis, the median survival time is less than three years and the fiveyear overall survival (OS) rate is only approximately $30 \%$ in most studies, even when treated intensively. However, AITL is not always lethal, with $30 \%$ of patients being long-term survivors $(1,2)$.

In the present study, the first case in which a relapsed and refractory AITL patient is successfully treated with a combination of bortezomib, mitoxantrone and dexamethasone (PAD regimen) is reported. The diagnosis, clinical features

Correspondence to: Dr Jian Hou, Department of Hematology, Shanghai Changzheng Hospital, The Second Military Medical University, 415 Fengyang Road, Shanghai 200003, P.R. China E-mail: houjian167@sohu.com

\section{${ }^{*}$ Contributed equally}

Key words: bortezomib, treatment, relapsed, refractory, angioimmunoblastic $\mathrm{T}$ cell lymphoma and bortezomib-based treatment of AITL according to this case are described and previously published data are also discussed. The study was approved by Ethical Principles for Conducting Research With Humans and Other Animals committee of The Second Military Medical University, Shanghai.

\section{Case report}

In September 2008, a 76-year-old female individual first visited an otorhinolaryngology clinic with the chief complaints of dyspnea and painful swelling of the throat. Physical examination revealed that her bilateral tonsils were projected beyond the midline with an irregular surface. Pharyngeal stenosis and lymphoid follicular hyperplasia were observed in the posterior wall of the pharynx. The bilateral cervical, axillary and inguinal lymph nodes were enlarged with moderate hardness and limited motion, as well as splenomegaly. A computed tomography (CT) scan of the chest showed multiple swollen lymph nodes in the mediastinal and bilateral axillary areas. Bone marrow cytomorphological examination and biopsy at that time were normal. A diagnosis of AITL was confirmed by biopsy of the enlarged cervical lymph node and bilateral tonsils. Immunohistochemical staining of the tumor cells showed CD4(+), CD8(+), CD10( \pm ), $\mathrm{Ki}-67(+), \mathrm{CD} 15(+), \mathrm{CD} 30(-), \mathrm{CD} 3(+), \mathrm{CD}^{+} 1^{+}$(vascular), $\mathrm{CD}^{+}{ }^{+}$(vascular), CXCL13(+) and follicular dendritic cell meshworks expressing CD21 (Fig. 1). T-cell receptor (TCR) $\gamma$ gene rearrangement $(+)$ and immunoglobulin (Ig) genes rearrangement (-) of the lymph nodes were detected by the polymerase chain reaction (PCR).

The patient was diagnosed with AITL IIIB. The patient achieved a partial response to the initial treatment with two cycles of CHOP (cyclophosphamide, doxorubicin, vincristine and prednisolone) and three cycles of CHOEP (cyclophosphamide, doxorubicin, vincristine, etoposide and prednisolone). However, after four months the disease had progressed. The patient then received two cycles of salvage therapy with EDCP (cisplatin, etoposide, cyclophosphamide and dexamethasone). The patient also received cyclosporine and thalidomide for two months. No response was observed. Between March 2009 and July 2009, the patient received 
A

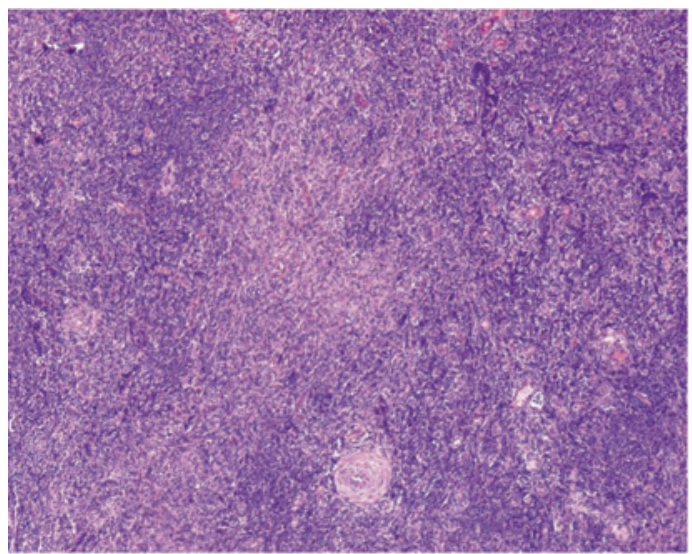

C

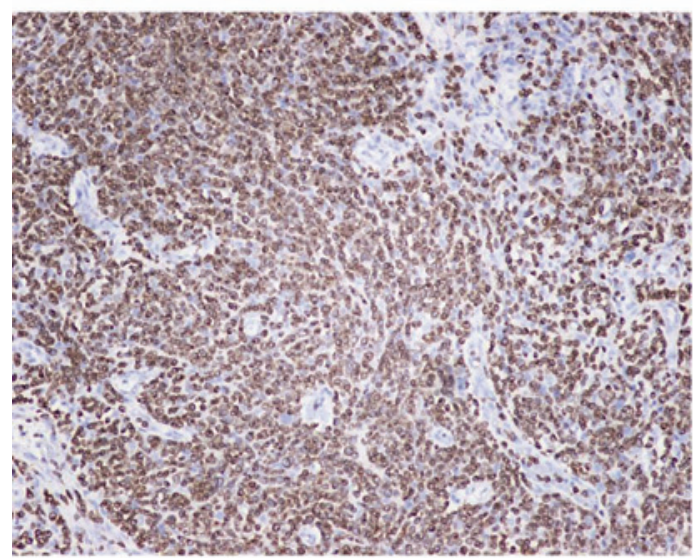

E

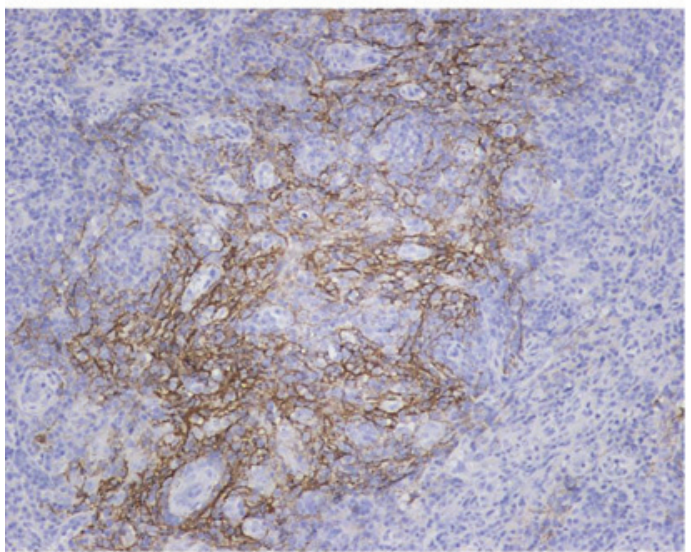

B

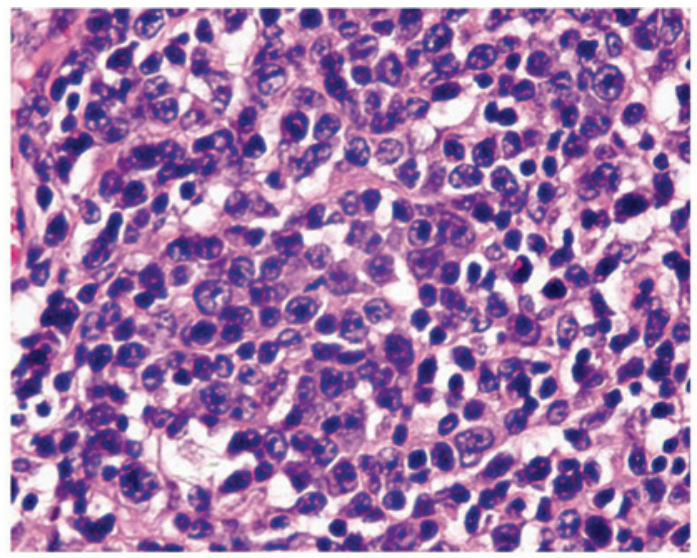

D

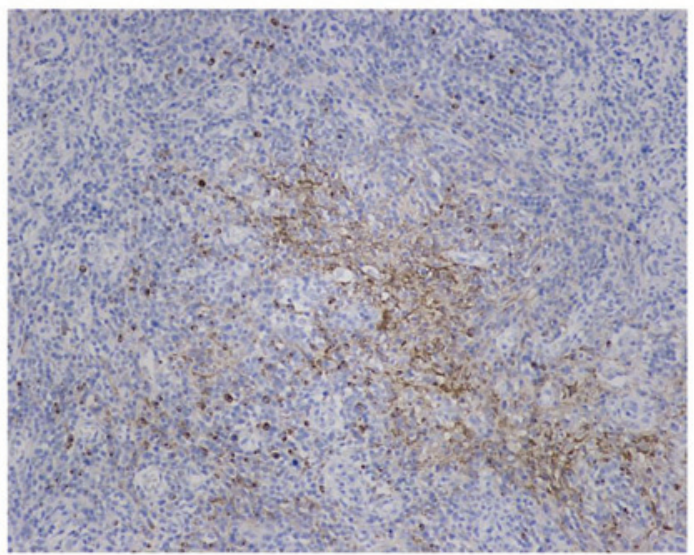

F

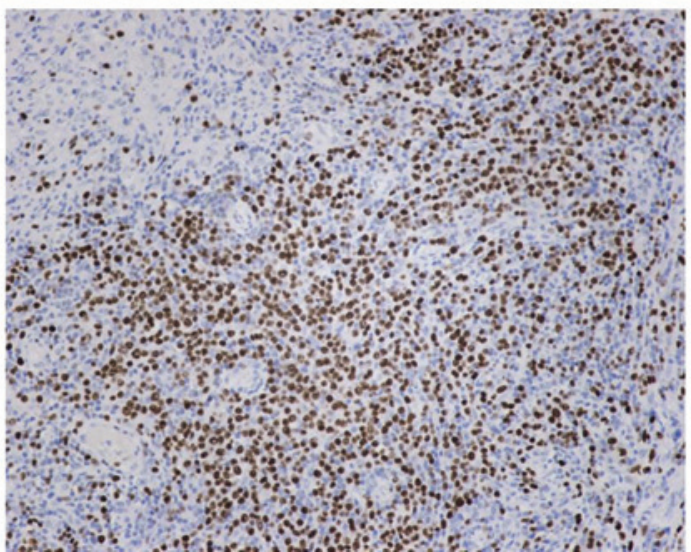

Figure 1. Lymph node biopsy. (A) Classical morphology with effacement of normal architecture and marked vascular proliferation associated with aggregates of atypical lymphoid cells (H\&E staining; x40 magnification). (B) The infiltrate is composed of medium to large lymphoid cells with abundant clear cytoplasm (H\&E staining; $x 400$ magnification). (C and D) The characteristic phenotype of tumor cells expressing (C) CD3, (D) CXCL13. (E) CD21 immunostaining emphasizes marked follicular dendritic entrapping high endothelial venules. (F) Immunohistochemistry shows homogeneous staining for Ki67.

five 28-day cycles of PAD regimen comprising $1.3 \mathrm{mg} / \mathrm{m}^{2}$ bortezomib, $2 \mathrm{mg} / \mathrm{m}^{2}$ mitoxantrone and $40 \mathrm{mg}$ dexamethasone on days $1,4,8$ and 11 , after signed informed consent was obtained. At the 18-month follow-up, the patient showed persistent clinical improvement, weight gain, disappearance of lymphadenopathy, improvement of performance status and no B symptoms, and complete response was achieved. The patient did not receive therapy until October 2010 when the patient was diagnosed as relapsed by positron emission tomography (PET). Subsequently, one cycle of COP and PAD were performed. However, severe myelosuppression and minor therapeutic effects were observed. The patient succumbed to a severe pulmonary infection in March 2011.

\section{Discussion}

AITL is a rare and aggressive malignancy which affects elderly adults at an age ranging from 59 to 65 years, clinically characterized by a sudden onset of constitutional symptoms, lymphadenopathy, hepatosplenomegaly, skin rash, bone marrow involvement, anemia (often hemolytic and Coombs-positive), polyclonal hypergammaglobulinemia and hypereosinophilia. Using PCR techniques, the detection of monoclonal or oligoclonal rearrangement of the TCR was found to be present in the majority of cases. In addition, the rearrangement of the Ig gene(s) was observed in up to onethird of patients (3). As yet, the standard therapeutic option 
for patients with AITL has not been clearly established. Various treatment strategies, which range from the CHOP or CHOP-like therapy to chemotherapy with autologous stem cell transplantation, even allogeneic transplantation, have proved to be largely unsuccessful in curing the disease. The lack of a demonstrated improvement in OS supports the development of novel approaches, including alemtuzumab (4), zanolimumab (5), denileukin diftitox (6), pralatrexate (7), histone deacetylase (HDAC) inhibitors (8), cyclosporine (9), thalidomide (10), gemcitabine (11) and bortezomib (12).

Bortezomib is a dipeptide boronic acid that selectively and potently inhibits the proteasome $26 \mathrm{~S}$ complex, exerting antitumor activity mainly via the inhibition of the NF- $\mathrm{kB}$ pathway components correlated with cell proliferation, apoptosis and angiogenesis (13). It has been reported that abnormal PRDM1 $\beta$ expression reflected poor prognosis in T-cell lymphoma, and that bortezomib is able to downregulate PRDM1 $\beta$ through $\mathrm{NF}-\mathrm{KB}$ inactivation (14). In vitro and in vivo studies demonstrated that bortezomib has the ability to eliminate tumor cell interaction with endothelial cells in T-cell leukemia/ lymphoma by affecting the expression of genes associated with the adhesion cascades (15). Therefore, bortezomib may play a special therapeutic role and be safe from the emergence of acute toxicity, which is important considering that AITL patients tend to be elderly adults with a number of concomitant medical problems.

A PAD regimen is commonly used to treat patients with multiple myeloma. To the best of our knowledge, this is the first reported case of the successful management of relapsed and refractory AITL with a combination of bortezomib, mitoxantrone and dexamethasone (PAD regimen). This combination was well tolerated and induced a complete and relatively sustained remission in this patient. We believe bortezomib was involved in the therapy of this patient since no response to anthracyclines and high-dose glucocorticoid was observed. Martínez-Delgado et al differentiated two subgroups of PTCL characterized by a high or reduced expression of the NF- $\mathrm{BB}$ pathway genes (16). Furthermore, Martínez-Delgado et al observed that a low expression of the NF- $\kappa \mathrm{B}$ pathway genes was significantly associated with short OS and may be an independent prognostic factor. Bortezomib not only acted on tumor cells themselves through $\mathrm{NF}-\kappa \mathrm{B}$ inactivation, but also removed tumor cell interaction with endothelial cells $(14,15)$. Therefore, we suggest that NF-kB-positive AITL patients treated with bortezomib have better results to treatment than NF- $\mathrm{KB}$-negative AITL patients.

Considering that heavy chemotherapy may cause serious adverse events in elderly adults, the use of the PAD regimen may be a reliable, safe and effective alternative for treating relapsed/refractory AITL. However, the efficacy of bortezomib should be elucidated in further larger-sized clinical trials with an extended follow-up. Furthermore, continued preclinical and clinical research is required to identify more effective treatment options for patients with relapsed/refractory AITL.

\section{References}

1. Vose J, Armitage J and Weisenburger D; International T-Cell Lymphoma Project: International peripheral T-cell and natural killer/T-cell lymphoma study: pathology findings and clinical outcomes. J Clin Oncol 26: 4124-4130, 2008.

2. Mourad N, Mounier N, Brière J, Raffoux E, Delmer A, Feller A, Meijer CJ, Emile JF, Bouabdallah R, Bosly A, Diebold J, Haioun C, Coiffier B, Gisselbrecht C, Gaulard P; Groupe d'Etude des Lymphomes de l'Adulte: Clinical, biologic, and pathologic features in 157 patients with angioimmunoblastic T-cell lymphoma treated within the Groupe d'Etude des Lymphomes de l'Adulte (GELA) trials. Blood 111: 4463-4470, 2008.

3. de Leval L, Gisselbrecht C and Gaulard P: Advances in the understanding and management of angioimmunoblastic T-cell lymphoma. Br J Haematol 148: 673-689, 2010.

4. Gallamini A, Zaja F, Patti C, Billio A, Specchia MR, Tucci A, Levis A, Manna A, Secondo V, Rigacci L, et al: Alemtuzumab (Campath-1H) and CHOP chemotherapy as first-line treatment of peripheral T-cell lymphoma: results of a GITIL (Gruppo Italiano Terapie Innovative nei Linfomi) prospective multicenter trial. Blood 110: 2316-2323, 2007.

5. d'Amore F, Radford J, Relander T, Jerkeman M, Tilly H, Osterborg A, Morschhauser F, Gramatzki M, Dreyling M, Bang B and Hagberg H: Phase II trial of zanolimumab (HuMax-CD4) in relapsed or refractory non-cutaneous peripheral $\mathrm{T}$ cell lymphoma. Br J Haematol 150: 565-573, 2010.

6. Dang NH, Pro B, Hagemeister FB, Samaniego F, Jones D, Samuels BI, Rodriguez MA, Goy A, Romaguera JE, McLaughlin P, et al: Phase II trial of denileukin diftitox for relapsed/refractory T-cell non-Hodgkin lymphoma. Br J Haematol 136: 439-447, 2007.

7. O'Connor OA, Pro B, Pinter-Brown L, Bartlett N, Popplewell L, Coiffier B, Lechowicz MJ, Savage KJ, Shustov AR, Gisselbrecht C, et al: Pralatrexate in patients with relapsed or refractory peripheral T-cell lymphoma: results from the pivotal PROPEL study. J Clin Oncol 29: 1182-1189, 2011.

8. Piekarz RL, Frye R, Prince HM, Kirschbaum MH, Zain J, Allen SL, Jaffe ES, Ling A, Turner M, Peer CJ, et al: Phase 2 trial of romidepsin in patients with peripheral T-cell lymphoma. Blood 117: 5827-5834, 2011.

9. Advani R, Horwitz S, Zelenetz A and Horning SJ: Angioimmunoblastic $\mathrm{T}$ cell lymphoma: treatment experience with cyclosporine. Leuk Lymphoma 48: 521-525, 2007.

10. Gottardi M, Danesin C, Canal F, Dei Tos AP, Stefani PM, Calistri E, Salvadori U and Gherlinzoni F: Complete remission induced by thalidomide in a case of angioimmunoblastic T-cell lymphoma refractory to autologous stem cell transplantation. Leuk Lymphoma 49: 1836-1838, 2008.

11. Arkenau HT, Chong G, Cunningham D, Watkins D, Sirohi B, Chau I, Wotherspoon A, Norman A, Horwich A and Matutes E: Gemcitabine, cisplatin and methylprednisolone for the treatment of patients with peripheral T-cell lymphoma: the Royal Marsden Hospital experience. Haematologica 92: 271-272, 2007.

12. Lee J, Suh C, Kang HJ, Ryoo BY, Huh J, Ko YH, Eom HS, Kim K, Park K and Kim WS: Phase I study of proteasome inhibitor bortezomib plus CHOP in patients with advanced, aggressive T-cell or NK/T-cell lymphoma. Ann Oncol 19: 2079-2083, 2008.

13. Sunwoo JB, Chen Z, Dong G, Yeh N, Crowl Bancroft C, Sausville E, Adams J, Elliott P and Van Waes C: Novel proteasome inhibitor PS-341 inhibits activation of nuclear factor-kappa B, cell survival, tumor growth, and angiogenesis in squamous cell carcinoma. Clin Cancer Res 7: 1419-1428, 2001.

14. Zhao WL, Liu YY, Zhang QL, Wang L, Leboeuf C, Zhang YW, Ma J, Garcia JF, Song YP, Li JM, et al: PRDM1 is involved in chemoresistance of T-cell lymphoma and down-regulated by the proteasome inhibitor. Blood 111: 3867-3871, 2008.

15. Shi WY, Wang L, Xiao D, Yao Y, Yang F, Jiang XX, Leboeuf C, Janin A, Chen SJ and Zhao WL: Proteasome inhibitor bortezomib targeted tumor-endothelial cell interaction in T-cell leukemia/ lymphoma. Ann Hematol 90: 53-58, 2011.

16. Martínez-Delgado B, Cuadros M, Honrado E, Ruiz de la Parte A, Roncador G, Alves J, Castrillo JM, Rivas C, Benítez J: Differential expression of NF-kappaB pathway genes among peripheral T-cell lymphomas. Leukemia 19: 2254-2263, 2005. 